\title{
VENEER BASED COMPOSITE HOLLOW UTILITY POLES MANUFACTURED FROM HARDWOOD PLANTATION THINNED TREES
}

\author{
Benoit P. Gilbert ${ }^{(1)}$, Ian D. Underhill ${ }^{(1)}$, Henri Bailleres ${ }^{(2)}$, Ali El Hanandeh ${ }^{(1)}$, Robbie L. McGavin ${ }^{(2)}$ \\ (1) Griffith School of Engineering, Griffith University, Australia \\ ${ }^{(2)}$ Salisbury Research Facility, Department of Agriculture, Fisheries and Forestry, Queensland Government, Australia \\ Corresponding author: b.gilbert@ griffith.edu.au
}

\begin{abstract}
Australia's utility pole network is aging and approaching its end of life. It is estimated that $70 \%$ of the 5 million poles currently in-service nationally were installed within the 20 years following the end of World War II and require replacement or remedial maintenance. Additionally, an estimated 21,700 high-durability new poles are required each year to support the expansion of the energy network. Utility poles were traditionally cut from native forest hardwood species. However, due to agreements which progressively phase out logging of native forests around Australia, finding new sources for utility poles presents a challenge. This paper presents the development of Veneer Based Composite hardwood hollow utility poles manufactured from mid-rotation Gympie messmate (Eucalyptus cloeziana) plantation thinned trees (also referred to as "thinning"), as an alternative to solid hardwood poles. The incentives behind the project and benefits of the proposed products are introduced in the paper. Small diameter poles, of nominal $115 \mathrm{~mm}$ internal diameter and $15 \mathrm{~mm}$ wall-thickness, were manufactured in two half-poles butt jointed together, using 9 hardwood veneers per half-pole. The poles were tested in bending and shear, and experimental test results are presented. The mechanical performance of the hollow poles is discussed and compared to hardwood poles sourced from mature trees and of similar size. Additionally, the required dimensions of the proposed hollow pole to replace actual solid poles are estimated. Results show that the proposed product represents a viable technical solution to the current shortage of utility poles. Future research and different options for improving the current concept are proposed in order to provide a more reliable and cost effective product for structural and architectural applications in general.
\end{abstract}




\section{INTRODUCTION}

Utility poles, commonly referred to as "power poles", support the energy network and therefore represent a vital part of the infrastructure in developed countries. Yet, Australia's utility pole network is aging and reaching its end of life, with $70 \%$ of the 5 million poles currently in-service nationally installed within the 20 years following the end of World War II [1]. Structural failure of one pole may have severe consequences on local communities and the economy in general.

The estimated investment required for the replacement or remedial maintenance of the aging 3.5 million Australian poles is as high as 1.75 billion Australian dollars (about 1.6 billion USD), based on an assumption of 500 Australian dollars per new pole [1]. Additionally, an estimated 21,700 high-durability new poles are required each year for extending the network and meeting energy demand, representing further investment of 13.5 million Australian dollars (about 12.2 billion USD) per year [1].

Hardwood utility poles have been traditionally used in Australia. Compared to more intensively manufactured steel, concrete or fibreglass poles, they are still thought to be the most economical and durable solution in terms of life-cycle costs [1]. Yet, due to growing environmental awareness and concerns over the sustainability of native forestry practices, agreements which progressively phase out logging of native forests around Australia have been signed [2]. In South-East Queensland where this project is originated, the South-East Queensland Forest Agreement (SEQFA) [3] was signed in 1999 and phases out logging of native forests by 2025, giving the industry 25 years to make the transition from Crown native forests to plantations and private forests. Consequently, the shortage of utility poles is expected to increase dramatically over the next decade while the demand is expected to rise sharply [1]. Finding long-term supply solutions to enable replacement of the aging poles presents a challenge.

Various alternative solutions to solid timber poles or columns have been proposed in the literature. Adam et. al. [4] analysed the feasibility, design strength and cost of hollow octagonal utility poles manufactured from composite wood flakes panels. The poles were tapered with the wall 
thickness decreasing with the height. Results indicated that the proposed poles were able to be cost competitive in the market place. Kyoto University has been intensively researching composite structures ranging from LVL cylinders [5, 6] to spirally cylindrical laminated veneer lumbers [7-9]. The latter product is manufactured through a continuous process with veneer tapes wound around a mandrel in clockwise and anticlockwise directions to form an interlocking pattern [7]. Low quality logs were used for the veneer tapes and the distance between butt jointed veneers was found to significantly influence the strength of the product [8]. Piao [10] manufactured 1.2 metres (small-scale) and 6 metres (full-scale) long nonagon hollow poles from knot free pine wood strips. While fullscale poles were not tested to failure, cantilever tests performed on the small-scaled poles showed that shear failure can govern the strength of the poles. Wehsener et. al. [11] have recently reported current research into fibre-reinforced moulded wooded tubes manufactured by shaping densified timber boards. The tubes have been used to support a 9 metres tall wind power plant.

This paper presents tests on Veneer Based Composite (VBC) hardwood hollow utility poles manufactured from mid-rotation Gympie messmate (Eucalyptus cloeziana) plantation thinned trees, also commonly referred to as "thinning", a species traditionally used in Australia for poles due to its favourable natural durability and strength properties [12]. The incentives of using hardwood plantation thinned trees and benefits of the proposed products are introduced in the paper. Six small diameter poles, of nominal $115 \mathrm{~mm}$ internal diameter and $15 \mathrm{~mm}$ wall-thickness, were manufactured in short lengths of $970 \mathrm{~mm}$. To determine their mechanical characteristics, four poles were tested in bending and two poles in predominant shear. Experimental test results are presented in the paper and a simple failure mechanism model in bending of the poles is also introduced and compared to experimental results. The mechanical performance of the hollow poles is discussed and compared to traditional hardwood poles of similar size cut from native forests. The required dimensions of the proposed hollow pole to replace traditional solid poles are also estimated. Future research and different options for improving the current concept are proposed in order to provide a more reliable and cost effective technical solution to the current shortage of utility poles. 
Research is currently underway on best connecting short lengths of VBC products to form useable beams and columns. The determination of the mechanical characteristics (stiffness and strength) of these connections is outside the scope of the present paper. Solutions that are currently being investigated are presented at the end of the paper. Furthermore, while the current research focuses on utility poles, due the reasons presented earlier, the proposed sections can also be used for various structural and architectural applications, such as building beams and columns, or alternatives to steel street lighting and traffic light poles.

\section{ECONOMIC AND ENVIRONMENATAL BENEFITS OF USING HARDWOOD PLAN- TATION THINNED TREES}

In hardwood plantations grown for high-quality solid wood products, an average of 1,000 stems per hectare are planted. However, only high quality trees are allowed to mature, with the lower quality trees (for instance, those that are crooked, smaller or have too many branches) removed in an operation referred to as "thinning" or "pre-commercial thinning". Typically, two main thinning operations occur. Nearly half of the trees (around 500) are cut at 1.5 to 3 years in the first thinning, with another 300 cut in the second thinning (mid rotation) at 10 to 15 years before the plantation is finally clear-felled at 25 to 35 years. The trees cut during the second thinning have a breast-high diameter (BHD) of about 15 to $30 \mathrm{~cm}$, and are deemed of little or no commercial value.

To justify continued expansion of Australia's current hardwood plantation estates, it is becoming necessary to develop high value end-use products for these small logs [13], as there are no clearly identified viable markets for these resources. Pulpwood was regarded as the only large scale viable option for these logs if the plantation is in close proximity (less than $100 \mathrm{~km}$ ) to a processing facility and/or forms part of an overall harvest scheme [13]. In more recent times, the international pulpwood market has become less attractive for Australian plantation growers. Additionally, with the uneconomical long crop rotation time of 25 to 35 years, the risks from fire, pests and adverse weather events increase dramatically each year while not translating into substantially higher finan- 
cial returns to the grower. More than 400,000 hectares of hardwood plantations have been planted around the year 2000 and a large quantity of mid rotation thinning logs are potentially immediately available, reinforcing the need to develop a market for this type of resource [14].

Various VBC structural applications using hardwood thinning veneers have been developed at Griffith University [14] in collaboration with the Salisbury Research Facility, Queensland Government, in an effort to develop high value end-use products for these mid-rotation logs. Advantages of the new products over sawn timber sections lie with the products (i) having efficient cross-sectional shapes, (i.e. hollow for the poles presented in this paper) and (ii) being able to be manufactured in large sizes currently not available in timber, as the manufacturing process [14] allow customising the dimensions of the product to meet a desired design capacity.

A study in Israel [15] has shown that short rotation plantations, based on harvesting $50 \%$ of the slower growing trees for use in the manufacture of Medium-density Fibreboard (MDF), as pulpwood or fire wood, could provide better returns to farmers. The current project may provide financial benefits to growers by creating a value-add industry. As a result, they may realise earlier return on investment after 10 to 15 years, instead of the current 25 to 35 years (particularly if the midrotation thinned trees are sold as low-grade veneer logs, and achieve prices of the lower end of large sawlogs of 30 to 40 Australian dollars per $\mathrm{m}^{3}$ ). Furthermore, environmental benefits may also be realised; for instance, increased carbon storage in long-term structural products as a result of the value-add products and the shorter plantation rotation $[16,17]$.

\section{EXPERIMENTAL STUDY}

\subsection{General}

Twelve half-poles were manufactured around a $115 \mathrm{~mm}$ diameter steel mandrel in lengths of 970 $\mathrm{mm}$. The manufacturing concept is detailed in [14] and uses the natural tendency of the veneers to roll about one side, making their gluing into half-shapes achievable around the mandrel, with the veneer grain orientated in the same direction (along the longitudinal axis of the pole). Each half- 
pole was manufactured at ambient temperature and moisture content using resorcinol formaldehyde structural adhesive from 9 Gympie messmate (Eucalyptus cloeziana) veneers of $1.7 \mathrm{~mm}$ nominal thickness, i.e. forming a nominal wall-thickness of $15 \mathrm{~mm}$. Veneers were delivered in sheets of 1.2 $\mathrm{m} \times 1.2 \mathrm{~m}$ and different sheets were randomly selected for each layer constituting a half-pole. Two half-poles were butt jointed together using structural epoxy resin to form a complete section, as shown in Figure 1.

Additionally, to determine the mechanical properties of each half-pole, $300 \mathrm{~mm} \times 500 \mathrm{~mm}$ flat Laminated Veneer Lumber (LVL) panels were also manufactured using veneer sections sourced from the same veneer sheets as each half-pole, glued in the exact same layering order.

Before testing, hollow poles and flat panels were stabilise at a constant temperature $\left(25^{\circ} \mathrm{C}\right)$ and relative humidity $(65 \%)$ until they reached equilibrium at an average measured oven-dry moisture content of $14.3 \%$.

\subsection{Bending tests}

\subsubsection{Test set-up}

Four timber poles were tested in a $500 \mathrm{kN}$ MTS universal testing machine in four point bending to determine their bending stiffness and bending capacity. The tests were run in displacement control and reached failure in about 7 minutes (Poles 1 and 2) and 4.5 minutes (Poles 3 and 4).

Each end of the poles was rigidly connected to a steel tube of length $L_{l}=1,045 \mathrm{~mm}$, as shown in Figure 2, to form beams of length $L=2,930 \mathrm{~mm}$, i.e. about 20 times the external diameter of the tested poles. At the connection with the steel tubes, i.e. at the load application points, polyester resin (pre-filled with $40 \%$ sawdust) was poured (see insert in Figure 2) (i) inside the poles to avoid ovalisation (local crushing) of the timber section and (ii) on the outside of the poles to match the inside diameter of the steel tube and ensure a tight fit between the two elements. Additionally, the steel tubes were slotted over $300 \mathrm{~mm}$ at their top and bottom, and a bolted device was used to sandwich the timber poles in the steel tubes, creating friction between the two elements. The butt joints between two half-poles lied in the horizontal plane. 
Three Linear Variable Displacement Transducers (LVDT) recorded the vertical displacement at the centre of the timber poles (LVDT 1) and at a distance $d=260 \mathrm{~mm}$ from their centre (LVDTs 2 and 3), as shown in Figure 2. The distance between LVDTs 2 and 3 of 3.6 times the pole diameter is slightly less than the recommend distance of five times the pole diameter in the European Standard EN 408 [18].

\subsubsection{Test results}

Table 1 provides the moment capacity $M_{b}$ of the poles calculated as,

$$
M_{b}=\frac{F_{\max }}{2} L_{1}
$$

where $F_{\max }$ is the total maximum applied load and $L_{l}$ is the distance from the supports to the points of application of the loads, as shown in Figure 2.

The bending stiffness $E_{p} I_{p}$ of the poles is also given in Table 1 and calculated by performing a linear regression on the linear portion of the load $F$-displacement curve,

$$
F=\frac{4 E_{p} I_{p}}{L_{1} d^{2}}\left(\delta_{1}-\frac{\delta_{2}+\delta_{3}}{2}\right)
$$

where $d$ the distance between two transducers and $\delta_{i}$ is the recorded displacement of LVDT number $i$. The second moment of area $I_{p}$ of the poles, calculated from measured external diameter and wallthickness, is also given in Table 1 for information. The load-displacement curves (see Eq. (2)) for all tested poles are given in Figure 3.

For Pole 2, failure developed at the compression side of the sample with the pole opening up, as shown in Figure 4. For Poles 1, 3 and 4, shear failure occurred at the connection between the timber poles and the steel tubes, and therefore the moment capacities $M_{b}$ given in Table 1 represent lower bound values of the actual capacity of the tested samples. Despite successive improvements of the test rig, the latter failure mode was not eliminated and the rig will need to be redesigned in the future. Yet, the moment capacities for Poles 1, 3 and 4 are within $2 \%$ of the capacities calculated using the simple failure mechanism model detailed in Section 4, suggesting that the shear failure in 
the steel/timber connection occurred at a similar applied moment than the failure mode introduced in Section 4.

\subsection{Shear tests}

\subsubsection{Test set-up}

Two timber poles were tested in a $500 \mathrm{kN}$ MTS universal testing machine in three point bending to determine their shear capacity. The tests were run in displacement control and reached failure in about 11 minutes (Pole 5) and 3.5 minutes (Pole 6).

The poles were simply supported, with a distance between supports of $L=820 \mathrm{~mm}$ (Pole 5) and $730 \mathrm{~mm}$ (Pole 6). The load was applied at the centre of the poles, as shown in Figure 5. To avoid local crushing, polyester resin (pre-filled with $40 \%$ sawdust) was poured inside the timber poles at the point of application of the load and at the supports. No resin was poured in the constant shear force areas between the load application point and the supports. The butt joints between two halfpoles lied in the horizontal plane for Pole 5 and vertical plane for Pole 6.

Three Linear Variable Displacement Transducers (LVDT) recorded the displacement at the centre of the timber poles (LVDT 1) and at a distance $d$ from the centre (LVDTs 2 and 3), as shown in Figure 5, with $d=410 \mathrm{~mm}$ for Pole 5 (i.e. at the supports) and $260 \mathrm{~mm}$ for Pole 6 .

\subsubsection{Test results}

The shear capacities $V_{s}$ of the poles, calculated as,

$$
V_{s}=\frac{F_{\max }}{2}
$$

where $F_{\max }$ is the maximum applied load, were found to be equal to $34.7 \mathrm{kN}$ for Pole 5 and $40.7 \mathrm{kN}$ for Pole 6. Using a close approximation of the shear area for tubes of half the cross-sectional area, this corresponds to maximum shear stresses $\tau_{s}$, calculated as,

$$
\tau_{s}=2 \frac{V_{s}}{A}
$$


where $A$ is the measured cross-sectional area of the poles, of $10.1 \mathrm{MPa}$ for Pole 5 and $12.4 \mathrm{MPa}$ for Pole 6. When compared to the shear strength of the material measured in Section 3.4.2, these values are $4.5 \%$ and $19.7 \%$ greater than the minimum of the average shear strengths of the two half-poles constituting Poles 5 and 6, respectively.

\subsection{Material testing}

\subsubsection{Tension and compression}

For the four poles tested in bending (see Section 3.2) and Pole 5 tested in predominant shear (See Section 3.3), tension and compression samples were cut from the flat panels of the half-poles undergoing tension and compression respectively. Coupon (dog bone) samples, with $50 \mathrm{~mm}$ wide $\times$ $225 \mathrm{~mm}$ long necks, were used in tension. For the compression samples, the flat panels were cut in two, reglued to form $30 \mathrm{~mm}$ nominal thick panels, and further cut into nominal $85 \mathrm{~mm}$ wide $\times 180$ mm long samples. For Pole 6, as the butt joint lied in the vertical plane (see Section 3.3.1), the two half-poles were undergoing both compression and tension and only compression samples were cut from the flat panels.

The tension and compression samples were tested following the method detailed in the Australian and New-Zealand Standard AS/NZS 4357.2 [19] in a $500 \mathrm{kN}$ MTS universal testing machine, at similar strain rates to the ones experienced by the tested poles. Three tension and compression samples were tested per half-pole.

The tensile $\sigma_{f, t e n s}$ and compressive $\sigma_{f, \text { comp }}$ strengths of the tension and compression samples, respectively, were calculated as,

$$
\sigma_{f, \text { tens }}=\frac{F_{\max }}{b d} \text { and } \sigma_{f, \text { comp }}=\frac{F_{\max }}{b d}
$$

where $F_{\max }$ is the maximum tensile or compressive applied load, and $b$ and $d$ are the measured width and depth of the tension or compression samples, respectively. The average measured strengths for all tested poles are given in Table 2 for Poles 1 to 5 and in Table 3 for Pole 6. 
Additionally, to accurately measure the Modulus of Elasticity (MOE) $E$ of the material and avoid measuring out-of-straightness deformations with the pure tension or compression deformations, two extensometers were positioned on opposite faces of the tension or compression samples. The MOE of each sample was calculated as the average of the MOE given by the two extensometers and measured by performing a linear regression on the linear portion of the stress-strain curves. The average measured MOE $E$ for all tested poles are given in Table 2 for Poles 1 to 5 and in Table 3 for Pole 6.

\subsubsection{Shear}

For Poles 5 and 6 tested in predominant shear (See Section 3.3), nominal $80 \mathrm{~mm}$ wide $\times 190 \mathrm{~mm}$ long samples were cut from the flat panels of each half pole constituting the two poles. The samples were tested following a similar method to the "two-rail test" method proposed in the ASTM D271913 [20]. Specifically, the samples were clamped between steel plates (as shown in Figure 6), leaving a shear area of $30 \mathrm{~mm} \times 80 \mathrm{~mm}$. The steel plates were serrated, preventing the timber panels from sliding between the steel plates. The grain of the LVL panels was orientated along the transverse (short) direction of the shear area, as shown in Figure 6. The angle $\theta$ between the applied load $F$ and the longitudinal (long) direction of the shear area was set to $14^{\circ}$, as shown in Figure 6.

A minimum of five samples per half pole were tested in a $30 \mathrm{kN}$ Lloyd universal testing machine, at similar shear strain rates to the ones experienced by the tested poles. Two samples per half-pole were fitted at their centre point with a $5 \mathrm{~mm}$ single strain gauge, orientated at $45^{\circ}$ to the longitudinal direction of the shear area (see Figure 6), so as to measure the shear modulus $G$.

The maximum shear stress $\tau_{f}$ of each sample is calculated as [20],

$$
\tau_{f}=\frac{F_{\max } \cos \theta}{L t}
$$

where $F_{\max }$ is the maximum applied load, and $L$ and $t$ are the measured length and thickness of the shear area, respectively. The shear modulus $G$ was calculated by performing a linear regression on the linear part of the shear stress $\tau$-strain curve [20], 


$$
\tau=\frac{F \cos \theta}{L t}=2 G \varepsilon
$$

where $\varepsilon$ is the strain recorded by the strain gauge.

The average measured maximum shear stress $\tau_{f}$ and shear modulus $G$ for all tested poles in predominant shear are given in Table 4.

\section{SIMPLE FAILURE MECHANISM MODEL IN BENDING}

This section develops a simple failure mechanism model of the timber poles in bending. The typical bending failure mode of sawn timber beams, triggered by brittle failure in the tensile side of the beam, is also hypothetically assumed for hollow timber poles. Perfect elastic-plastic (as encountered in Section 3.4) and brittle behaviours of the LVL in compression and tension, respectively, are considered herein. Typically, timber fails in tension at a higher stress than in compression (see Table 2) and plastic deformation would occur in the compressive side of the poles before brittle failure occurs in the tensile side. In reference to Figure 7 and for a hollow pole with the butt joint between half-poles coinciding with the centreline of the pole, the bending stress $\sigma(x)$ at a distance $x$ from the centreline would be given as,

$$
\sigma(x)=\left\{\begin{array}{l}
\sigma_{f, \text { comp }} \text { if } x \geq 0 \text { and } \varepsilon(x) \geq \varepsilon_{\text {plastic }} \\
E_{\text {comp }} \varepsilon(x) \text { if } x \geq 0 \text { and } \varepsilon(x) \leq \varepsilon_{\text {plastic }} \\
E_{\text {tens }} \varepsilon(x) \text { if } x \leq 0
\end{array}\right.
$$

where $E_{\text {comp }}$ and $E_{\text {tens }}$ are the MOE of the half-poles mainly undergoing compression and tension, respectively, $\varepsilon(x)$ is the strain at a distance $x$ from the centreline and $\varepsilon_{\text {plastic }}$ is the value of the compressive strain where plastification occurs (i.e. at a compressive stress of $\sigma_{f, \text { comp }}$ ), given as,

$$
\varepsilon_{\text {plastic }}=\frac{\sigma_{f, \text { comp }}}{E_{\text {comp }}}
$$

The internal compressive and tensile forces $F_{\text {comp }}$ and $F_{\text {tens }}$ in the pole, respectively, are calculated as, 


$$
F_{\text {comp }}=\iint_{x=d}^{x=\frac{D}{2}} \sigma(x) d A(x) \text { and } F_{\text {tens }}=\iint_{x=-\frac{D}{2}}^{x=d} \sigma(x) d A(x)
$$

where $D$ is the external diameter of the pole, $d$ is the shift in the neutral axis due to the plastification in the compressive side of the pole and $d A(x)$ is the differential cross-sectional area, as shown in Figure 7. The bending moment $M$ in the pole is then given as,

$$
M=-F_{\text {comp }} e=F_{\text {tens }} e
$$

where $e$ is the lever arm between the resultants of the tensile and compressive forces, as shown in Figure 7.

Assuming that failure occurs when the tensile stress reaches the tensile strength $\sigma_{f, \text { tens }}$ at $x=-D / 2$ $+t_{\text {tens }} / 2$ (i.e. at an average stress in the bottom wall of the pole of $\sigma_{f, t e n s}$, as shown in Figure 7 , where $t_{\text {tens }}$ is the wall thickness of the half-pole mainly undergoing tension), the moment capacity $M_{b}$ of the pole is calculated by solving $F_{\text {tens }}=-F_{\text {comp }}$ in Eq. (10) and finding the shift in neutral axis $d$ and lever $\operatorname{arm} e$.

Table 5 gives the moment capacity $M_{b}$ numerically calculated for each tested pole in Section 3.2 by using the calculated MOE and strengths given in Table 2, and measured external diameter $D$ and wall-thickness $t_{\text {comp }}$ and $t_{\text {tens }}$ of the half-poles mainly undergoing compression and tension, respectively. Comparison with actual moment capacities, given in Table 1, is also provided in Table 5.

Results in Table 5 show that the simple failure mechanism model provides a good approximation of the actual moment capacity of the poles. Furthermore, Table 5 suggests that the observed failure modes in Section 3.2.2 result in similar or slightly lower moment capacity $M_{b}$ than the typical brittle bending failure mode of timber beams considered in the present failure mechanism model. The model can therefore be used in subsequent sections to estimate the capacity of poles of different external diameters and wall thickness than the ones tested in this paper. 


\section{DISCUSION}

\subsection{Comparison with solid poles of similar size}

The Australian and New Zealand standard AS/NZS 4676 [21] classifies timber utility poles in seven strength groups ranging from minimum bending characteristic strength $f_{b}^{\prime}$ of $100 \mathrm{MPa}$ (Strength group S1) to $25 \mathrm{MPa}$ (Strength group S7), and minimum shear characteristic strength $f_{s}{ }_{s}$ of 7.2 MPa (Strength group S1) to $2.5 \mathrm{MPa}$ (Strength group S7). Considering a wind peak load duration of less than 5 seconds, the moment capacity $M_{b}$ of a full length preservative treated, unshaved and not steamed solid pole is given as [21],

$$
M_{b}={f^{\prime}}_{b} Z
$$

where $Z$ is the section modulus. The shear capacity $V_{s}$ is given as [21],

$$
V_{s}=f^{\prime}{ }_{s} A_{s}
$$

where $A_{s}$ is the shear plane area, equal to 3/4 the cross-sectional area for solid round cross-sections.

Therefore, a $145 \mathrm{~mm}$ diameter solid utility pole sourced from mature trees would have a minimum moment capacity $M_{b}$ of $29.93 \mathrm{kN} . \mathrm{m}$ in Strength group S1, i.e. 1.6 times more than the maximum capacity found in Table 1 (Pole 3), and of 7.48 kN.m in Strength group S7, i.e. 1.9 less than the minimum capacity found in Table 1 (Pole 4).

Specifically in terms of moment capacity, tested Poles 1 to 3 would be classified in Strength group S4 and tested Pole 4 would be classified in Strength group S5. While the investigated poles fall in intermediate strength groups, their cross-sectional area is 2.7 times less than a solid utility pole of the same overall dimension, in other words, the hollow poles are about 2.7 times lighter than solid hardwood utility poles of the same overall dimension. Note that unseasoned native forest Gympie Messmate timber is classified in Strength group S2 [22].

In terms of shear capacity, the performance of the tested poles in Section 3.3 is less than for the bending capacity. The poles would be classified in Strength groups S6 (Pole 6) and S7 (Pole 5). 


\subsection{Alternative solution to in-service utility poles}

\subsubsection{Survey of a utility pole network configuration in SEQ}

In order to determine an actual configuration of the current utility pole network in South-East Queensland (SEQ) and assess the ability of the proposed VBC hollow poles to replace in-service utility poles, 95 poles were surveyed in Molendinar, near Griffith University. Specifically, 48 and 47 poles were surveyed in an industrial and residential area, respectively, in terms of pole diameter (at breast-height), number of conductors, conductor elevations and distance between two consecutive poles.

For both industrial and residential areas, two sets of conductors were typically observed. $71 \%$ of the poles (34 poles) in the industrial area had 3 conductors near the tip of the pole and 4 conductors at a lower elevation. $77 \%$ of the poles (36 poles) in the residential area had 4 conductors near the tip of the pole and 2 conductors at a lower elevation. The elevations of the two sets of conductors were measured using a laser distance measurer. The distance from the top set of conductors to the tip of the pole was estimated to be about $30 \mathrm{~cm}$. The distance between two consecutive poles was estimated at $+/-5 \%$.

Table 6 gives the average measured pole diameter, elevations of each set of conductors and distance between two consecutive poles.

Therefore, using the average surveyed configurations of utility poles given in Table 6 and a conductor overall diameter of $25 \mathrm{~mm}$, a $10.5 \mathrm{~m}$ high and $375 \mathrm{~mm}$ diameter utility pole in a South-East Queensland industrial area would be subjected to a design bending moment $M^{*}=197.2 \mathrm{kN} . \mathrm{m}$ and a shear force $V^{*}=25.2 \mathrm{kN}$. Similarly, a $9 \mathrm{~m}$ high and $325 \mathrm{~mm}$ diameter utility pole in a South-East Queensland residential area would be subjected to a design bending moment of $M^{*}=114.1 \mathrm{kN} . \mathrm{m}$ and a design shear force $V^{*}=16.8 \mathrm{kN}$. See AS/NZS 4676 [21] and Appendix A for detailed calculations. 


\subsubsection{Estimated dimensions of VBC hollow utility poles for the surveyed SEQ industrial area}

The dimensions of VBC hollow poles to potentially replace existing utility poles encountered in the surveyed South-East Queensland industrial area is estimated in this section. Tension, compression and shear strength characteristic values of $70 \mathrm{MPa}, 55 \mathrm{MPa}$ and $9 \mathrm{MPa}$, respectively, are assumed herein for the plantation hardwood thinning LVL used in the manufacturing process. These values are in the order of magnitude of the lower capacities of the material tested in Section 3.4.

Using the simple failure mechanism model developed in Section 4 (with MOE $E=18 \mathrm{GPa}$ ), a load duration factor of 1.0 (wind peak load duration of less than 5 seconds) and a capacity factor $\phi$ $=0.9[21]$, a $375 \mathrm{~mm}$ (external diameter) $\times 40 \mathrm{~mm}$ (wall thickness) hollow pole would have a design moment capacity $\phi M_{b}$ of $213.8 \mathrm{kN}$.m. In terms of shear strength, Eq. (4) would give a design shear capacity $\phi V_{s}$ of $170.5 \mathrm{kN}$. Therefore, these design moment and shear capacities are greater than the design bending moment $\left(M^{*}=197.2 \mathrm{kN} . \mathrm{m}\right)$ and shear force $\left(V^{*}=25.2 \mathrm{kN}\right)$, respectively, experienced by actual utility poles, as encountered in a South-East Queensland industrial area (See Section 5.2.1 and Appendix A). The bending and shear action-to-capacity ratios are equal to 0.92 and 0.14 respectively.

The proposed hollow poles consequently represent a viable technical solution to the current shortage of traditional solid hardwood utility poles. While the proposed poles would have only an external diameter 1.16 times greater than the average surveyed diameter of $322.3 \mathrm{~mm}$ (see Table 6), they would have a cross-sectional area 1.93 times smaller than the average surveyed pole. This reduction in mass of nearly a factor of 2 would significantly facilitate handling. Additionally, the manufacturing process would allow the wall thickness to gradually decrease with the height of the poles, further reducing the overall mass of the hollow poles.

It may be noted that contrary to traditional solid utility poles, the proposed hollow poles are not intended to be buried in the ground but connected above ground to a steel or concrete footing, therefore considerably limiting termite attacks and reducing decay hazards. Therefore, no pole degrada- 
tion factor, as preconised in the AS/NZS 4676 [21], is considered herein. The axial compressive stress was found to be negligible compared to the bending stress and was ignored in the above calculation.

\subsubsection{Estimated dimensions of VBC hollow utility poles for the surveyed SEQ residential area}

Similarly to previous Section 0 , a $325 \mathrm{~mm}$ (external diameter) $\times 30 \mathrm{~mm}$ (wall thickness) hollow pole would have a design moment capacity $\phi M_{b}$ of $123.9 \mathrm{kN} . \mathrm{m}$ and a design shear capacity $\phi V_{s}$ of 112.6 $\mathrm{kN}$. Therefore, these design moment and shear capacities are greater than the design bending moment $\left(M^{*}=114.1 \mathrm{kN} . \mathrm{m}\right)$ and shear force $\left(V^{*}=16.8 \mathrm{kN}\right)$, respectively, experienced by actual utility poles, as encountered in a surveyed South-East Queensland residential area (See Section 5.2.1 and Appendix A). The bending and shear action-to-capacity ratios are equal to 0.92 and 0.15 respectively.

The proposed poles would have an external diameter 1.17 times greater than the average surveyed diameter of $277.6 \mathrm{~mm}$ (see Table 6), and a cross-sectional area 2.37 times smaller than the average surveyed pole.

\subsection{Future research}

The final structural aim of the current research is to establish probability-based limit state design criteria for the proposed sections, resulting in immediate benefits to the community. Current studies undertaken intend to (i) investigate the influence of the high proportion of natural defects in small diameter thinned trees on the strength and variability in the mechanical properties of composite products and (ii) understand the behaviour and particular failure modes of the hollow sections (as shown in Figure 4).

Additionally, the shear capacity of the hollow profiles is low and may govern the design if the profiles are used for structural and architectural applications other than utility poles. Future studies will investigate cross-laminating the veneers at angles of $+/-10^{\circ}$ with the pole longitudinal axis 
(similar to [8]). This configuration will likely increase the shear capacity of the poles while marginally reducing their moment capacity.

Importantly, due to the limited log length that peeling lathes can accommodate (1.2 metres long for the lathe used in this project), short lengths of VBC products are currently manufactured. To manufacture usable lengths (greater than or equal to 9 metres for utility poles), jointing subsections presents some challenges. Solutions currently investigated include manufacturing the products in a continuous process, similar to LVL products, or inserting a steel sleeve in the hollow-form of similar stiffness and strength to the VBC product.

It is essential to have a comprehensive understanding of the environmental impacts of the product in order to formulate a valid statement about its sustainability. Life cycle assessment (LCA) is a standardized method under the ISO14040:2006 [23]. LCA provides a systematic way to evaluate a product's life cycle environmental impacts from cradle to grave, thus eliminating shifting the impacts from one phase of the product or service life to another. LCA will be used to evaluate the environmental performance of $\mathrm{VBC}$ in comparison to alternative utility poles materials.

\section{CONCLUSION}

This paper presented bending, shear and material experimental tests on VBC hardwood hollow utility poles manufactured from mid-rotation hardwood plantation thinned trees (thinning). Four poles were tested in bending and two poles were tested in predominant shear. A simple failure mechanism model of the pole in bending was able to accurately reproduce the actual bending failure capacities. Ninety-five poles were surveyed in an industrial and residential area in South-East Queensland, and actual in-service pole network configurations were drawn for this region. Using the simple failure mechanism model, results show that the proposed hollow poles are a viable technical solution to the current shortage of traditional solid hardwood utility poles. The hollow utility poles would have an external diameter about 1.2 times greater than currently in-service poles but would be about 2 times lighter. The proposed hollow sections also have the potential to be used in 
various structural and architectural applications. Future research directions are presented in the paper.

\section{ACKNOWLEDGMENT}

The authors would like to thank the Department of Agriculture, Fisheries and Forestry, Australian Government and Forest and Wood Products Australia for their financial support through the “2012, Science and innovation award for young people in agriculture, fisheries and forestry”, Forestry category. Mr John Clark, former undergraduate student at Griffith University, is also acknowledged for his help in the testing campaign and performing the survey of in-service utility poles. 


\section{REFERENCES}

[1] L. Francis, J. Norton, Australian timber pole resources for energy networks, A review, Department of Primary Industry and Fisheries, Queensland Government, Brisbane, Australia, 2006.

[2] Australian Government, Department of Agriculture Fisheries and Forestry, Regional Forest Agreements, http://www.daff.gov.au/forestry/policies/rfa, Accessed on 01/06/2013.

[3] Queensland Government, Department of Environment and Resource Management, South East Queensland Forests Agreement (SEQFA), http://www.timberqueensland.com.au/Growing/SEQFA.aspx, Accessed on 01/06/2013.

[4] R.D. Adams, G.P. Krueger, A.E. Lund, D.D. Nicholas, "Development of utility poles from composite wood material", Proceedings of the 7th IEEE/PES Transmission and Distribution Conference and Exposition (Ed.: IEEE Service center), Atlanta, U.S.A., 37-40, 1979.

[5] H. Sasaki, S. Kawai "Recent research and development work on wood composites in Japan", Wood Science and Technology, 28, 241-248, 1994.

[6] Y. Hara, S. Kawai, H. Sasaki "Manufacture and mechanical properties of cylindrical laminated veneer lumber", Japan Wood Research Society, 81, 28-30, 1994.

[7] T. Hata, K. Umemura, H. Yamauchi, A. Nakayama, S. Kawai, H. Sasaki "Design and pilot production of a spiral-winder for the manufacture of cylindrical laminated veneer lumber", Journal of Wood Science, 47, 115-123, 2001.

[8] P. Berard, P. Yang, H. Yamauchi, K. Umemura, S. Kawai "Modeling of a cylindrical laminated veneer lumber I: mechanical properties of hinoki (Chamaecyparis obtusa)and the reliability of a nonlinear finite elements model of a four-point bending test", Journal of Wood Science, 1-7, 2011.

[9] P. Berard, P. Yang, H. Yamauchi, K. Umemura, S. Kawai "Modeling of a cylindrical laminated veneer lumber II: a nonlinear finite element model to improve the quality of the butt joint", Journal of Wood Science, 1-7, 2011.

[10] C. Piao, Wood laminated composite poles, PhD Thesis, School of renewable natural ressources, Louisiana State University, Louisiana, U.S.A., 2003.

[11] J. Wehsener, T. Werner, J. Hartig, P. Haller, "Advancements for the structural application of fiberreinforced moulded wooden tubes", Proceedings of the RILEM Conference "Materials and Joints in Timber Structures - Recent Advancement of Technology" (Eds.: S. Aicher, H.-W. Reinhardt, H. Garrecht), Stuttgart, Germany, 99-108, 2013.

[12] K.R. Bottle, Wood in Australia, Types, properties and uses, (McGraw-Hill), Sydney, Australia, 1983.

[13] R.L. McGavin, M.P. Davies, J. Macgregor-Skinner, H. Bailleres, M. Armstrong, W.J. Atyeo, J. Norton, Utilisation Potential and Market Opportunities for Plantation Hardwood Thinnings from Queensland and Northern New South Wales, PN05.2022, Department of Primary Industries and Fisheries, Queensland Department, 2006.

[14] I.D. Underhill, B.P. Gilbert, H. Bailleres, R.L. McGavin, D. Patterson, "Structural Veneer Based Composite products from hardwood thinning - Part I: Background and manufacturing", Proceedings of the RILEM Conference "Materials and Joints in Timber Structures - Recent Advancement of Technology" (Eds.: S. Aicher, H.-W. Reinhardt, H. Garrecht), Stuttgart, Germany, 577-588, 2013.

[15] Y. Zohar, A. Gafni, J. Morris, S. Shalhevet "Eucalyptus plantations in Israel: an assessment of economic and environmental viability", New Forests, 36, 135-157, 2008.

[16] H. Baral, R.J. Keenan, J.C. Fox, N.E. Stork, S. Kasel "Spatial assessment of ecosystem goods and services in complex production landscapes: a case study from south-eastern Australia", Ecological Complexity, 13, 35-45, 2013.

[17] D.F. Grigal, W.E. Berguson "Soil carbon changes associated with short-rotation systems.", Biomass and Bioenergy, 14, 371-377, 1998.

[18] EN 408, Timber structures - Structural timber and glued laminated timber - Determination of some physical and mechanical properties, European Committee for Standardization (CEN), Brussels, Belgium, 2010.

[19] AS/NZS 4357.2, Structural laminated veneer lumber, Part 2: Determination of structural properties Test methods, Standards Australia, Sydney, Australia, 2006.

[20] ASTM D2719-13, Standard test methods for structural panels in shear through-the-thickness, ASTM International, Pennsylvania, USA, 2013. 
[21] AS/NZS 4676, Structural design requirements for utility services poles, Standards Australia, Sydney, Australia, 2000.

[22] AS/NZS 2878, Timber - Classification into strength groups, Standards Australia, Sydney, Australia, 2000.

[23] ISO 14040, Environmental management - Life cycle assessment - Principles and framework, International Organization for Standardization, Geneva, Switzerland, 2006. 
Table 1: Four point bending test results

\begin{tabular}{c|ccc}
\hline Pole & $M_{b}(\mathrm{kN} . \mathrm{m})$ & $E_{p} I_{p}\left(\mathrm{kN} . \mathrm{mm}^{2}\right)$ & $I_{p}\left(\mathrm{~mm}^{4}\right)$ \\
\hline 1 & 17.45 & $2.67 \times 10^{8}$ & $1.40 \times 10^{7}$ \\
2 & 17.25 & $2.30 \times 10^{8}$ & $1.39 \times 10^{7}$ \\
3 & 18.38 & $2.28 \times 10^{8}$ & $1.47 \times 10^{7}$ \\
4 & 14.42 & $1.60 \times 10^{8}$ & $1.43 \times 10^{7}$ \\
\hline
\end{tabular}

Table 2: Average MOE and tensile and compressive strengths for Poles 1 to 5 (material testing)

\begin{tabular}{|c|c|c|c|c|c|c|c|c|}
\hline \multirow[b]{2}{*}{ Pole } & \multicolumn{4}{|c|}{ Half-pole in compression $^{(1)}$} & \multicolumn{4}{|c|}{ Half-pole in tension $^{(1)}$} \\
\hline & $\begin{array}{l}\sigma_{f, \text { comp }} \\
(\mathrm{MPa})\end{array}$ & $\mathrm{CoV}$ & $\begin{array}{c}E \\
(\mathrm{GPa})\end{array}$ & $\mathrm{CoV}$ & $\begin{array}{c}\sigma_{f, \text { tens }} \\
(\mathrm{MPa})\end{array}$ & $\mathrm{CoV}$ & $\begin{array}{c}E \\
(\mathrm{GPa})\end{array}$ & $\mathrm{CoV}$ \\
\hline 1 & 61.3 & 0.068 & 17.9 & 0.071 & 94.7 & 0.038 & 19.2 & 0.034 \\
\hline 2 & 60.8 & 0.019 & 17.9 & 0.048 & 90.3 & 0.049 & 19.1 & 0.044 \\
\hline 3 & 66.2 & 0.020 & 20.9 & 0.017 & 84.9 & 0.050 & 18.8 & 0.025 \\
\hline 4 & 55.9 & 0.030 & 15.8 & 0.030 & 68.5 & 0.066 & 15.7 & 0.007 \\
\hline 5 & 54.7 & 0.031 & $16.3^{(2)}$ & - & 106.6 & 0.043 & 20.2 & 0.044 \\
\hline
\end{tabular}

(1): Three samples were tested per half-pole

${ }^{(2)}$ : Due to technical issues, the extensometers only recorded MOE for one sample out of three

Table 3: Average MOE and compressive strength for Pole 6 (material testing)

\begin{tabular}{|c|c|c|c|c|c|c|c|c|}
\hline \multirow[b]{2}{*}{ Pole } & \multicolumn{4}{|c|}{$1^{\text {st }}$ half pole ${ }^{(1)}$} & \multicolumn{4}{|c|}{$2^{\text {nd }}$ half pole ${ }^{(1)}$} \\
\hline & $\begin{array}{l}\sigma_{f, \text { comp }} \\
(\mathrm{MPa})\end{array}$ & $\mathrm{CoV}$ & $\begin{array}{c}E \\
(\mathrm{GPa})\end{array}$ & $\mathrm{CoV}$ & $\begin{array}{l}\sigma_{f, \text { comp }} \\
(\mathrm{MPa})\end{array}$ & $\mathrm{CoV}$ & $\begin{array}{c}E \\
(\mathrm{GPa})\end{array}$ & $\mathrm{CoV}$ \\
\hline 6 & 54.3 & 0.061 & 16.7 & 0.045 & 56.0 & 0.009 & 16.5 & 0.042 \\
\hline
\end{tabular}

${ }^{(1)}$ : Three samples were tested per half-pole

Table 4: Average maximum shear stress and shear modulus for all poles tested in predominant shear (material testing)

\begin{tabular}{c|cccc|cccc}
\hline & \multicolumn{4}{|c|}{$1^{\text {st }}$ half pole } & \multicolumn{4}{c}{$2^{\text {nd }}$ half pole $^{(2)}$} \\
\cline { 2 - 9 } Pole & $\begin{array}{c}\tau_{f} \\
(\mathrm{MPa})\end{array}$ & $\mathrm{CoV}$ & $\begin{array}{c}G \\
(\mathrm{GPa})\end{array}$ & $\mathrm{CoV}$ & $\begin{array}{c}\tau_{f} \\
(\mathrm{MPa})\end{array}$ & $\mathrm{CoV}$ & $(\mathrm{GPa})$ & $\mathrm{CoV}$ \\
\hline $5^{(3)}$ & 9.6 & 0.036 & 625 & 0.037 & 11.7 & 0.075 & 748 & 0.023 \\
6 & 10.0 & 0.027 & 773 & 0.004 & 11.3 & 0.065 & 707 & 0.014 \\
\hline
\end{tabular}

${ }^{(1)}$ : Five samples were tested per half-pole. Only two samples per half-pole were fitted with strain gauges

${ }^{(2)}$ : Six samples were tested for Pole $52^{\text {nd }}$ half-pole and five samples for Pole $62^{\text {nd }}$ half-pole. Only two samples per halfpole were fitted with strain gauges

${ }^{(3)}$ : For Pole 5 , the $1^{\text {st }}$ half pole is undergoing compression and the $2^{\text {nd }}$ half pole is undergoing tension

Table 5: Simple failure mechanism model results

\begin{tabular}{c|cc}
\hline Pole & $M_{b}$ (model) $(\mathrm{kN} . \mathrm{m})$ & $M_{b}$ (model) $/ M_{b}$ (test) \\
\hline 1 & 17.63 & 1.01 \\
2 & 17.11 & 0.99 \\
3 & 17.99 & 0.98 \\
4 & 14.76 & 1.02 \\
\hline
\end{tabular}


Table 6: Average surveyed configurations of an in-service utility pole network in South-East Queensland

\begin{tabular}{ccccccccc}
\hline Area & $\begin{array}{c}\text { Pole diam. } \\
(\mathrm{mm})\end{array}$ & $\mathrm{CoV}$ & $\begin{array}{c}\text { Elev. bottom } \\
\text { conduc. }(\mathrm{m})\end{array}$ & $\mathrm{CoV}$ & $\begin{array}{c}\text { Elev. top } \\
\text { conduc. }(\mathrm{m})\end{array}$ & $\mathrm{CoV}$ & $\begin{array}{c}\text { Dist. btw } \\
\text { poles }(\mathrm{m})\end{array}$ & $\mathrm{CoV}$ \\
\hline Industrial $^{(1)}$ & $322.3^{(3)}$ & 0.117 & 7.78 & 0.103 & 10.26 & 0.077 & 45.9 & 0.237 \\
Residential $^{(2)}$ & $277.6^{(4)}$ & 0.110 & 6.34 & 0.093 & 8.49 & 0.079 & 35.6 & 0.242 \\
\hline
\end{tabular}

${ }^{(1)}: 48$ poles were surveyed in the industrial area.

${ }^{(2)}: 47$ poles were surveyed in the residential area.

${ }^{(3)}$ : Due to attachments running along the poles, the diameter was only able to be measured on 42 poles.

${ }^{(4)}$ : Due to attachments running along the poles, the diameter was only able to be measured on 21 poles. 


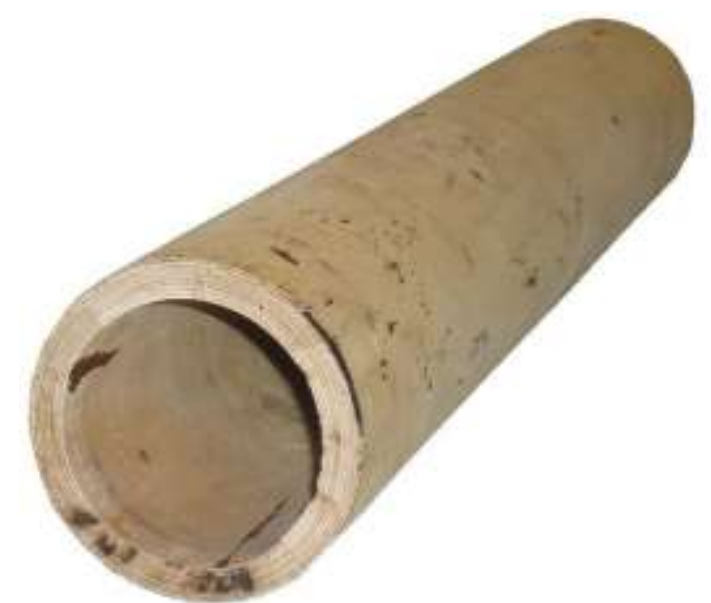

Figure 1: Example of a manufactured pole

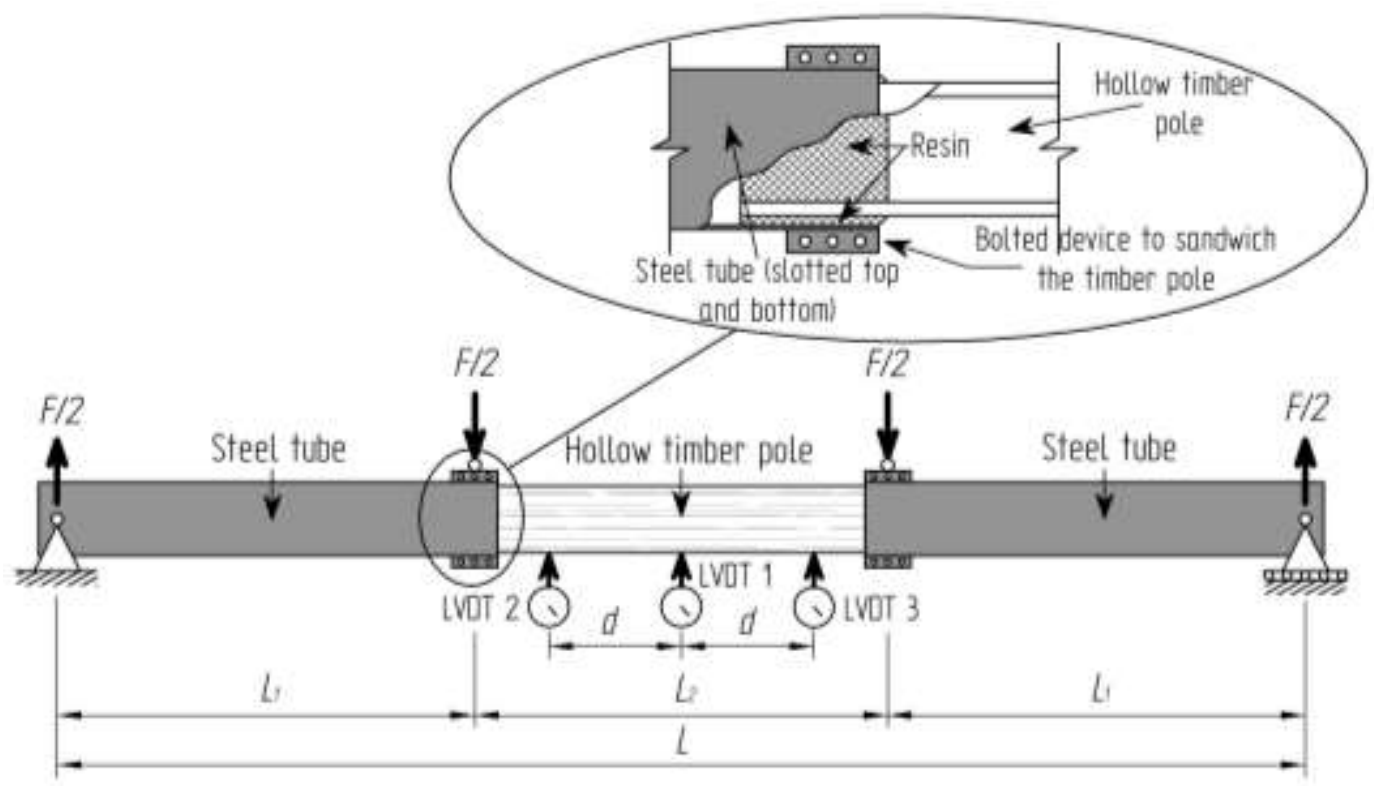

Figure 2: Four point bending test set-up

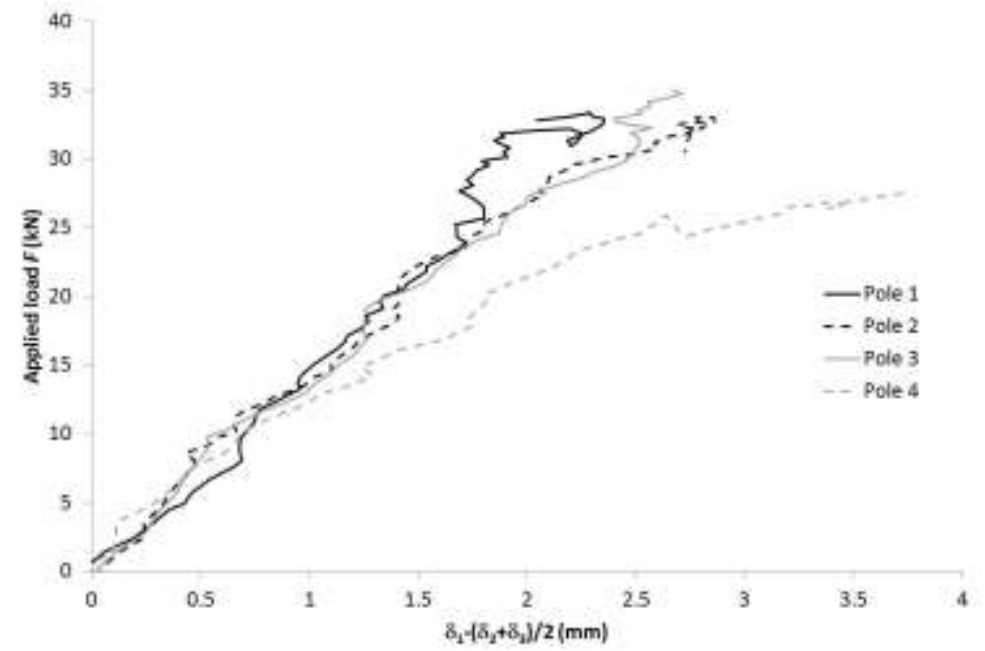

Figure 3: Load-displacement curves for all tested poles in four point bending 


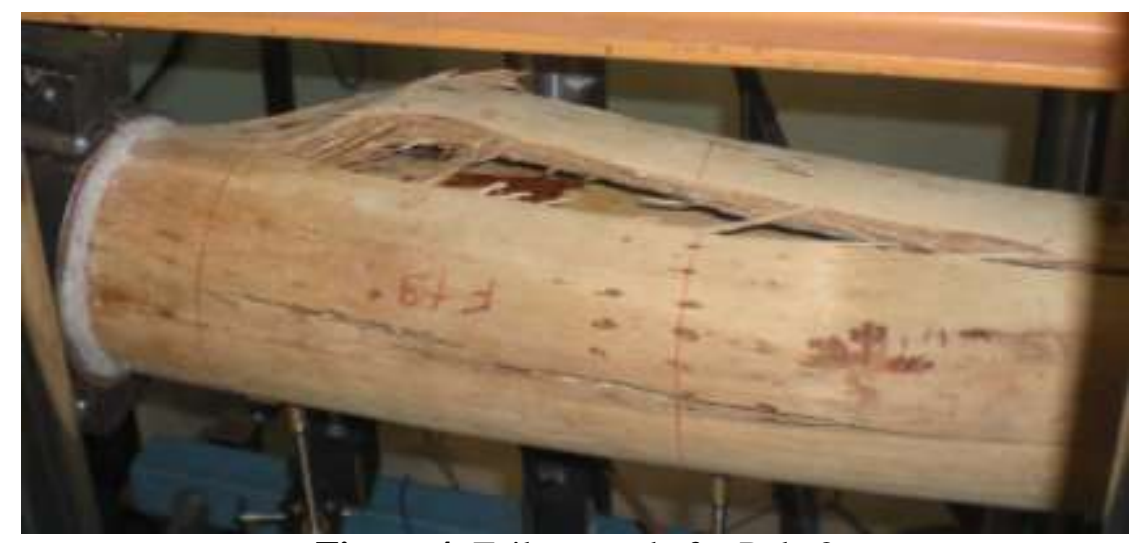

Figure 4: Failure mode for Pole 2

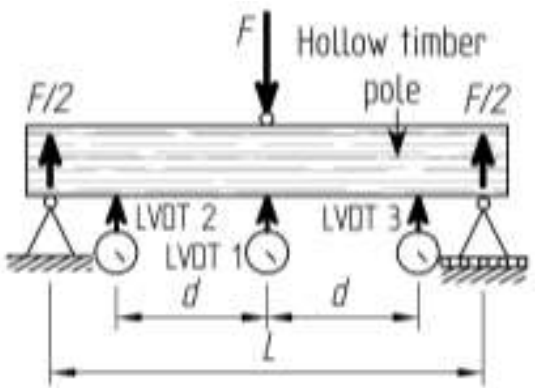

Figure 5: Three point bending test set-up

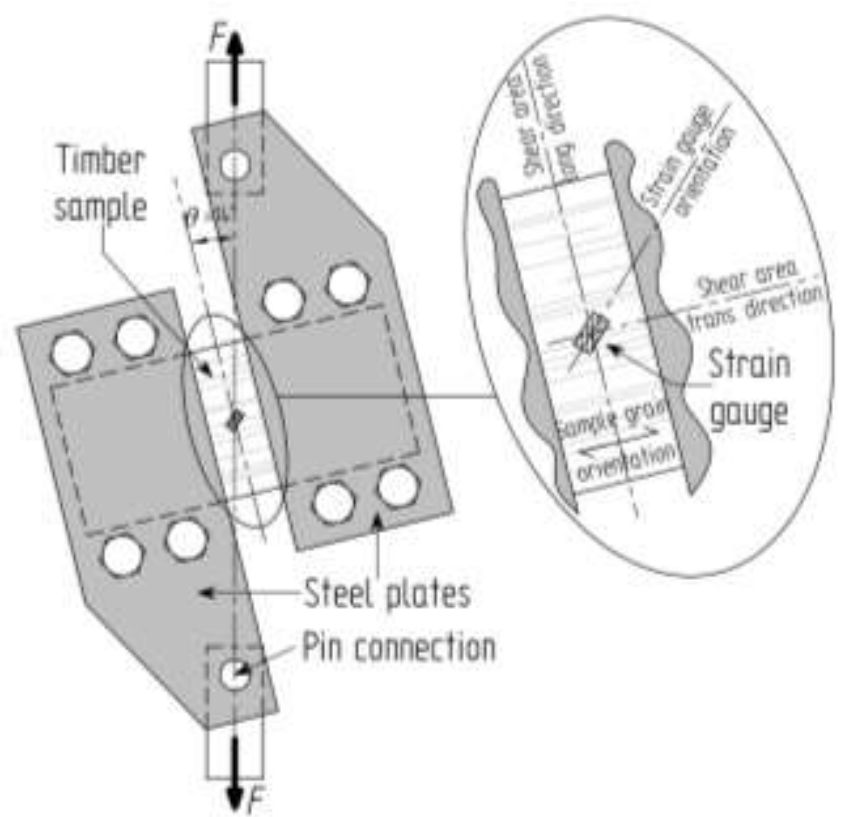

Figure 6: Shear sample test set-up 


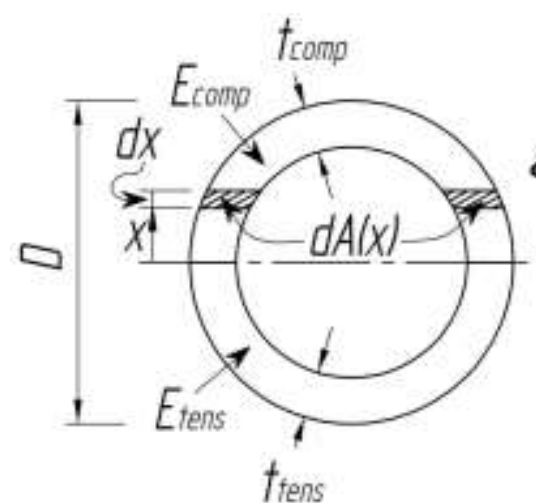

(a)

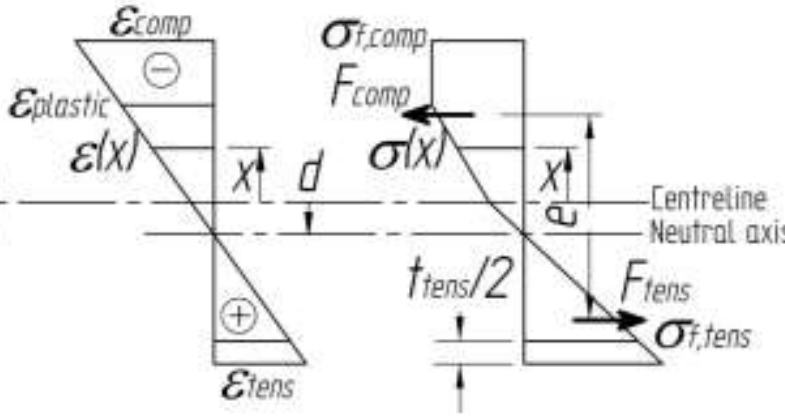

(b) (c)

Figure 7: Simple failure mechanism in bending, (a) pole cross-section, (b) strain distribution and (c) stress distribution 


\section{APPENDIX A: WIND ACTIONS}

\section{A1. SCOPE}

This appendix presents the calculations to determine the wind actions on poles, as encountered in the surveyed industrial and residential areas, following the Australian/New Zealand standard AS/NZS 4676:2000.

\section{A2. WIND PRESSURE}

The horizontal design wind pressure $P_{d}(z)$ at an elevation $z$ from the ground is given in Eq. (E2) of the AS/NZS 4676 and expressed as,

$$
P_{d}(z)=p_{b} K_{Z} K_{T} C_{D}
$$

where,

- $p_{b}=$ the basic regional wind pressure, given in Table E1 of the AS/NZS 4676 and equal to 2.2 $\mathrm{kPa}$ for South-East Queensland (Intermediate region).

- $K_{Z}=$ the height factor, given in Table E2 of the AS/NZS 4676. For "Terrain Category" 2.5 (i.e. between well-scattered (less than $5 \mathrm{~m}$ high) and closely spaced (between $3 \mathrm{~m}$ to $10 \mathrm{~m}$ high) obstructions), $K_{Z}=0.64$ for $z \leq 3 \mathrm{~m}, 0.70$ for $3 \mathrm{~m}<z \leq 5 \mathrm{~m}, 0.85$ for $5 \mathrm{~m}<z \leq 10 \mathrm{~m}$ and 0.95 for 10 $\mathrm{m}<z \leq 15 \mathrm{~m}$. Intermediate values of $K_{Z}$ may be obtained by linear interpolation between previous values.

- $K_{T}=$ the topographical factor, determined in Section E5 of the AS/NZS 4676. A flat terrain is assumed herein and $K_{T}$ is taken as 1.0.

- $C_{D}=$ the drag factor, given in Table E4 of the AS/NZS 4676 and equal to 1.2 for the circular timber poles and bundled conductors.

\section{A3. WIND LOAD FROM CONDUCTORS}


The horizontal wind load $F_{a w}$ from a conductor acting on the pole is given in Eq. (3.7(3)) of the AS/NZS 4676 and expressed as,

$$
F_{a w}=p_{d} d_{c} k_{c} L_{w}
$$

where,

- $p_{d}=$ the design wind pressure at the conductor elevation, given in Eq. (A14).

- $d_{c}=$ the nominal external diameter of the conductor.

- $k_{e}=$ a span factor, given in Table 3.7 .3 of the AS/NZS 4676 and equal to 1.0 for the conductor spans considered herein (less than $100 \mathrm{~m}$ ).

- $L_{w}=$ the wind span or the average distance between two adjacent poles herein.

\section{A4. WIND ACTIONS ON A POLE}

The design bending moment $M^{*}$ experienced by a pole with two sets of conductors is given as,

$$
M^{*}=\int_{z=0}^{z=\text { Pole Height }} p_{d}(z) d_{p} z d z+F_{a w, b} h_{b}+F_{a w, t} h_{t}
$$

where,

- $d_{p}=$ the nominal external diameter of the pole.

- $F_{a w, b}$ and $F_{a w, t}=$ the wind loads from the bottom and top sets of conductors, respectively.

- $h_{b}$ and $h_{t}=$ the elevations of the bottom and top sets of conductors, respectively.

The design shear force $V^{*}$ experienced by a pole with two sets of conductors is given as,

$$
V^{*}=\int_{z=0}^{z=\text { Pole Height }} p_{d}(z) d_{p} d z+F_{a w, b}+F_{a w, t}
$$

A load factor of 1.0 is used in previous Eqs. (A16) and (A17).

\section{A4.1 WIND ACTIONS ON AN ACTUAL SEQ INDUSTRIAL AREA POLE}

The typical pole configuration encountered in the surveyed SEQ industrial area is shown in Figure A1. The configuration is based on the observed number of conductors, the average surveyed 
heights of each set of conductors and the average surveyed distance between two adjacent poles (wind span). A nominal external diameter $d_{c}$ of $25 \mathrm{~mm}$ is assumed for the conductors.

For a $375 \mathrm{~mm}$ nominal external diameter pole, Eqs. (A16) and (A17) give a design bending moment $M^{*}=197.2 \mathrm{kN} . \mathrm{m}$ and a shear force $V^{*}=25.2 \mathrm{kN}$, respectively. For the conductors, intermediate values of $K_{z}=0.784$ and 0.854 at elevations $z=7.8 \mathrm{~m}$ and $10.2 \mathrm{~m}$, respectively, are used.

\section{A4.2 WIND ACTIONS ON A REPRESENTATIVE SEQ RESIDENTIAL AREA POLE}

The typical pole configuration as encountered in the surveyed SEQ residential area is shown in Figure A2. Similarly to Section A4.1, the configuration is based on the observed number of conductors, the average surveyed heights of each set of conductors and the average surveyed distance between two adjacent poles (wind span). A nominal external diameter $d_{c}$ of $25 \mathrm{~mm}$ is also assumed for the conductors.

For a $325 \mathrm{~mm}$ nominal external diameter pole, Eqs. (A16) and (A17) give a design bending moment $M^{*}=114.1 \mathrm{kN} . \mathrm{m}$ and a shear force $V^{*}=16.8 \mathrm{kN}$, respectively. For the conductors, intermediate values of $K_{z}=0.739$ and 0.805 at elevations $z=6.3 \mathrm{~m}$ and $8.5 \mathrm{~m}$, respectively, are used. 


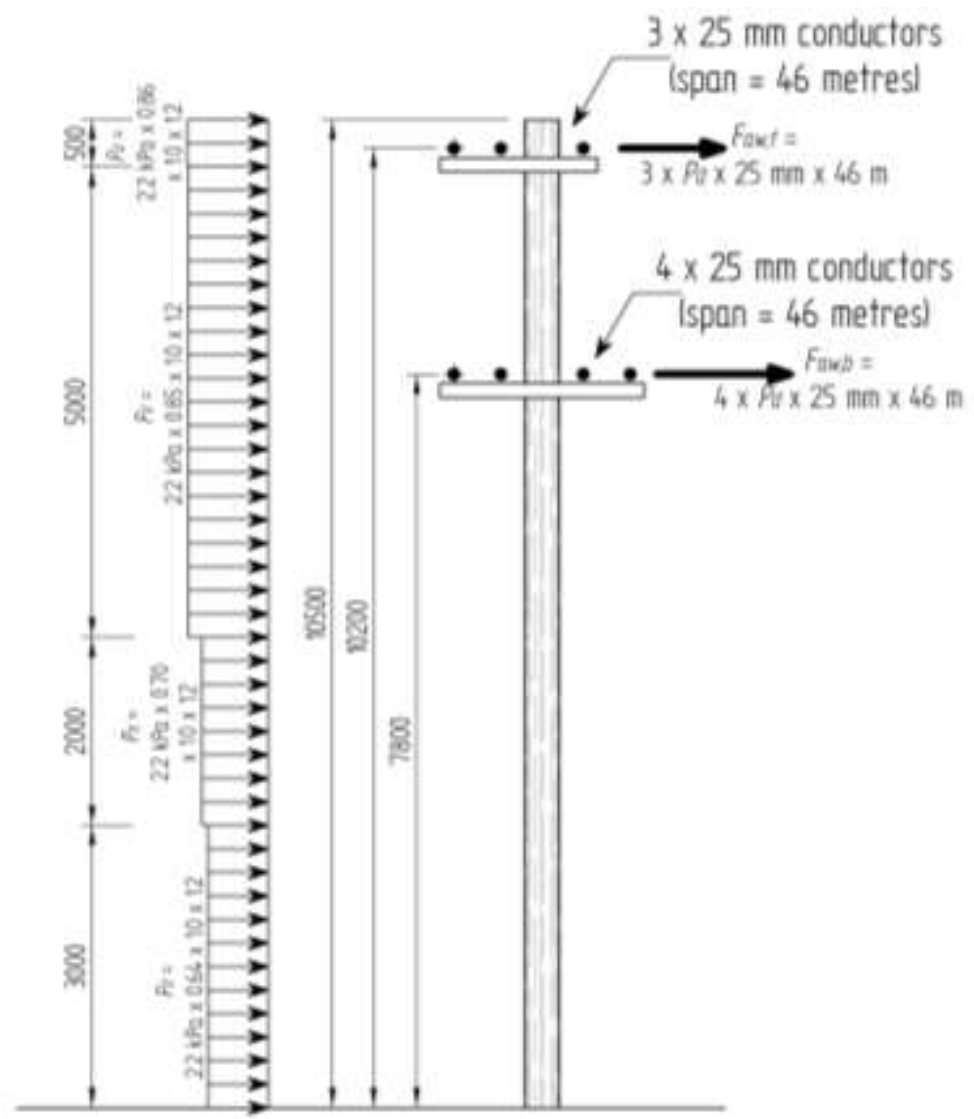

Figure A1: Typical utility pole configuration in the surveyed SEQ industrial area

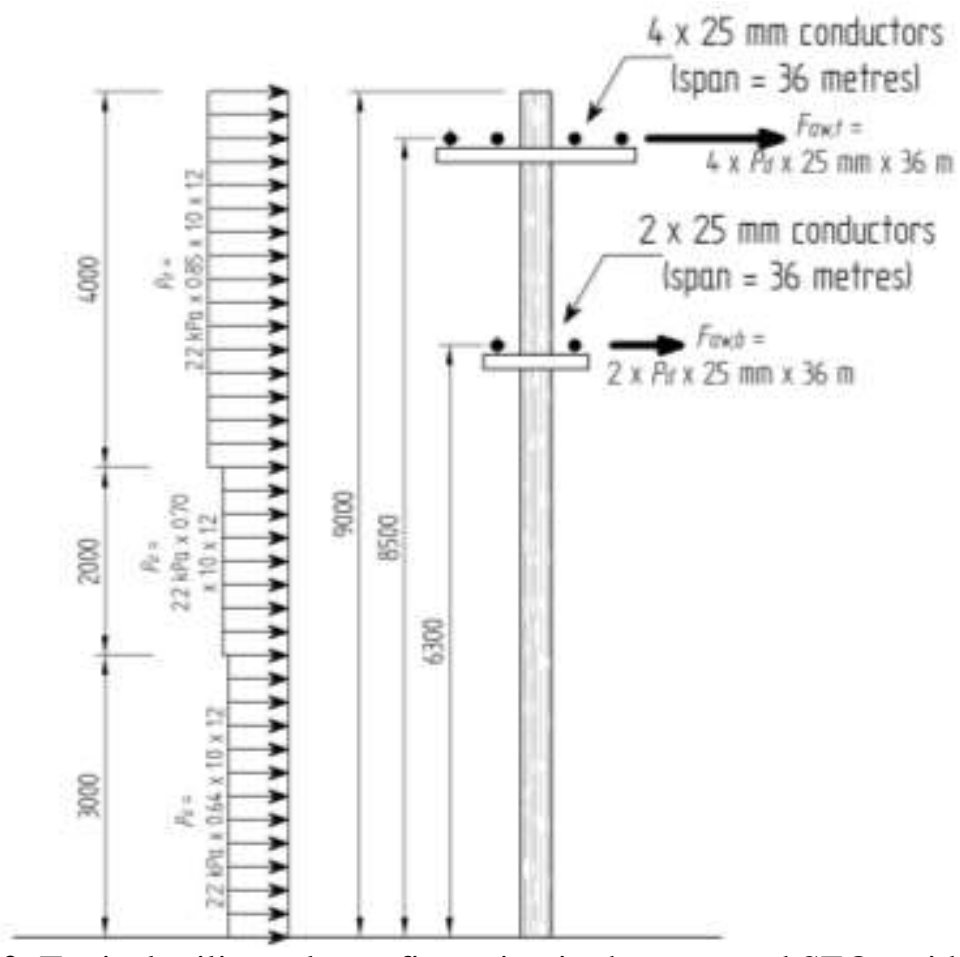

Figure A2: Typical utility pole configuration in the surveyed SEQ residential area 
